\title{
Quality assurance of spectral ultraviolet measurements in Europe through the development of a transportable unit (QASUME)
}

\section{Alkiviadis F. Bais, Mario Blumthaler, Julian Gröbner, Gunther Seckmeyer, Ann Ruth Webb, et al.}

Alkiviadis F. Bais, Mario Blumthaler, Julian Gröbner, Gunther Seckmeyer, Ann Ruth Webb, Peter Gorts, Tapani Koskela, Diana Rembges, Stelios Kazadzis, Josef Schreder, Peter Cotton, Peter Kelly, Natalia Kouremeti, Kimo Rikkonen, H. Studemund, Rick Tax, Sigrid Wuttke, "Quality assurance of spectral ultraviolet measurements in Europe through the development of a transportable unit (QASUME)," Proc. SPIE 4896, Ultraviolet Ground- and Space-based Measurements, Models, and Effects II, (1 July 2003); doi: $10.1117 / 12.468641$

Event: Third International Asia-Pacific Environmental Remote Sensing Remote Sensing of the Atmosphere, Ocean, Environment, and Space, 2002, Hangzhou, China 


\title{
Quality Assurance of Spectral Ultraviolet Measurements in Europe Through the Development of a Transportable Unit (QASUME)
}

\author{
Alkiviadis F. Bais ${ }^{\mathrm{a}^{*}}$, Mario Blumthaler ${ }^{\mathrm{b}}$, Julian Gröbner ${ }^{\mathrm{c}}$, Gunther Seckmeyer ${ }^{\mathrm{d}}$, Ann R. Webb ${ }^{\mathrm{e}}$, Peter \\ Gorts $^{\mathrm{f}}$, Tapani Koskela ${ }^{\mathrm{g}}$, Diana Rembges ${ }^{\mathrm{c}}$, Stelios Kazadzis ${ }^{\mathrm{a}}$, Josef Schreder ${ }^{\mathrm{b}}$, Peter Cotton ${ }^{\mathrm{e}}$, Peter \\ Kelly $^{\mathrm{e}}$, Natalia Kouremeti ${ }^{\mathrm{a}}$, Kimo Rikkonen ${ }^{\mathrm{g}}$, H. Studemund ${ }^{\mathrm{d}}$, Rick Tax ${ }^{\mathrm{f}}$, Sigrid Wuttke ${ }^{\mathrm{d}}$ \\ ${ }^{\mathrm{a}}$ Aristotle University of Thessaloniki, ${ }^{\mathrm{b}}$ University of Innsbruck, \\ ${ }^{c}$ Institute for Health \& Consumer Protection, ${ }^{\mathrm{d}}$ University of Hanover, \\ ${ }^{\mathrm{e}}$ University of Manchester Institute of Science and Technology, \\ ${ }^{\mathrm{f}}$ National Institute of Public Health and the Environment, ${ }^{\mathrm{g}}$ Finnish Meteorological Institute
}

\begin{abstract}
QASUME is a European Commission funded project that aims to develop and test a transportable unit for providing quality assurance to UV spectroradiometric measurements conducted in Europe. The comparisons will be performed at the home sites of the instruments, thus avoiding the risk of transporting instruments to participate in intercomparison campaigns. Spectral measurements obtained at each of the stations will be compared, following detailed and objective comparison protocols, against collocated measurements performed by a thoroughly tested and validated travelling unit. The transportable unit comprises a spectroradiometer, its calibrator with a set of calibration lamps traceable to the sources of different Standards Laboratories, and devices for determining the slit function and the angular response of the local spectroradiometers. The unit will be transported by road to about $25 \mathrm{UV}$ stations over a period of about two years.

The spectroradiometer of the transportable unit is compared in an intercomparison campaign with six instruments to establish a relation, which would then be used as a reference for its calibration over the period of its regular operation at the European stations. Different weather patterns (from clear skies to heavy rain) were present during the campaign, allowing the performance of the spectroradiometers to be evaluated under unfavourable conditions (as may be experienced at home sites) as well as the more desirable dry conditions. Measurements in the laboratory revealed that the calibration standards of the spectroradiometers differ by up to $10 \%$. The evaluation is completed through comparisons with the same six instruments at their homes sites.
\end{abstract}

\section{INTRODUCTION}

During the last decade a large number of monitoring stations has been established worldwide for monitoring the spectrum of solar ultraviolet radiation reaching the Earth's surface. UV monitoring is considered as one of the most important activities, which was stimulated in the last years by the observed decreases in stratospheric ozone ${ }^{1}$. Moreover, the association of solar UV radiation with damages on humans and on the ecosystem in general and its strong relation to atmospheric chemistry imposed the necessity of performing high quality spectral UV measurements, which would help substantially in addressing these issues. Given that UV represents only a very small part of the solar spectrum, its measurement becomes very difficult, requiring high-level technology as well as sophisticated instrumentation and procedures $^{2}$. The need for quality control (QC) and quality assurance (QA) of UV measurements has been recognised already since the beginning of the 1990's. The establishment of international databases of European UV measurements (e.g. the European UV Database established in the frame of SUVDAMA and EDUCE EC funded projects and the WMO database, WOUVDC, established by Environment Canada) and particularly their opening to the users' community is calling for strict application of QC/QA procedures in order to ensure the quality and comparability of the data ${ }^{3}$.

QC is performed at the monitoring stations through the development and application of appropriate procedures, most of which have been already tested and verified through international collaboration between UV instrument operators. It is however uncertain on how many of the existing UV stations proper quality control is performed. Until now, QA has been achieved -with particular success- mainly through participation of instruments in intercomparison campaigns. As

\footnotetext{
* abais@ auth.gr; phone +30 310998184; fax +03 310248602; Aristotle University of Thessaloniki, Physics Dept., 54124 - Thessaloniki, Greece 
the number of deployed instruments is constantly increasing, such campaigns seem now impracticable, in addition to the risk of damaging the instruments or altering their optical characteristics during transportation and the interruption of their regular records for long intervals.

The QASUME project is a pilot study, aiming at providing Quality Assurance to solar UV measurements conducted presently by spectroradiometers operating in Europe, as an alternative to intercomparison campaigns. The underpinning idea is to compare spectral global UV measurements at a number of stations with those of a collocated travelling spectroradiometer, following objective comparison protocols. The transportable unit is validated and thoroughly tested in an intercomparison campaign against a set of seven UV spectroradiometers and during an evaluation round at the home sites of these instruments.

If the result of the project is successful, it is planned to permanently establish this unit for long-term operation in order to continue serving all interested European Institutes after the end of the project. JRC will undertake to host, maintain and operate this unit in the future, providing significant services in maintaining the quality of UV measurements in Europe. This objective can be proved of great importance considering the continuous deployment of new instruments in all countries in the European continent.

\section{DESCRIPTION OF THE TRANSPORTABLE UNIT}

The unit comprises a UV spectroradiometer, a portable calibrator with a set of five calibration lamps, and two devices for the determination of the spectral resolution and the angular response of the local spectroradiometers.

\subsection{The spectroradiometer}

The UV spectroradiometer belongs to the Joint Research Centre (JRC) of the European Commission and is a commercial double monochromator spectroradiometer (DM-150) from Bentham, UK, optimized for measurements of global solar ultraviolet irradiance. The radiation is sampled with an input optic (specially shaped teflon diffuser) connected to the entrance slit of the spectroradiometer through a $4 \mathrm{~m}$ long optical quartz fiber. The integrated directional response of the input optic deviates less than $2 \%$ from the ideal angular response. The scanning spectrometer uses two gratings of 2400 grooves $/ \mathrm{mm}$, which in conjunction with the entrance and exit slits result in spectral resolution of about $0.8 \mathrm{~nm}$ (FWHM). Its spectral range extends from 250 to $500 \mathrm{~nm}$, and the scans are normally performed in steps of $0.25 \mathrm{~nm}$. The whole system is temperature stabilized, to within $0.5^{\circ} \mathrm{C}$.

\subsection{The Calibrator}

The calibrator was developed by the University of Hanover, Institute of Meteorology and Climatology and was optimized to operate with the spectroradiometer of the transportable unit. It has an octagon shape in order to minimize reflections on the walls and the lamp is cooled by natural convection of air. This ensures that the lamps behave in the same way as in a dark room. It uses 100 Watt FEL type lamps, instead of 1000 Watt, because they produce lees heat and give sufficient power at the chosen distance of $40 \mathrm{~cm}$ from the input optic of the spectrometer. The five calibration lamps are traceable to the PTB standards. At each calibration three lamps are measured to assure consistency in the spectroradiometers calibration, the other two kept as a reserve in case of disagreement of one of the three lamps. It should be mentioned that the calibrator is used mainly to check maintain the stability of the spectroradiometer between transportations, and its absolute calibration is performed at the laboratory of JRC using 1000 Watt FEL lamps.

\subsection{The angular response device}

The angular response of a spectroradiometer is an essential parameter for assessing the quality of its spectral measurements and for applying corrections in case it deviates from the ideal response $e^{4,5}$. Therefore a device for the measurement of the spectral response of the local spectroradiometers has been included in the travelling unit. This device, which is still under development and testing, uses a 400 Watt Ultramed lamp manufactured by OSRAM that has very strong signal in the UV, and the light is directed on the diffuser of the spectroradiometer with the aid of a $2 \mathrm{~m}$ light guide. The light guide is mounted on an arm that can rotate $\pm 88^{\circ}$ from the vertical and is positioned at the desired angle with the aid of a stepping motor to within $0.05^{\circ}$. The arm is mounted on a plate that can rotate about its vertical axis allowing the measurement of the angular response at various azimuths. The light is focused on the entrance of the light guide by a concentrator lens, thus it is not necessary to use a diffuser to homogenize the output beam, and the fibers of the light guide are scrambled to further improve homogenization. The intensity of the lamp is monitored continuously with the aid of a silicon photodiode mounted at the one end of a $0.3 \mathrm{~m}$ light guide, the other end of which samples the light from the lamp 
without obscuring the operation of the main guide. This signal is used to normalize the intensity of the measured irradiance accounting for changes in the lamp's intensity with time.

\subsection{Measurement of spectral resolution}

The spectral resolution is also an important parameter of a spectroradiometer, especially when tools for the detection of wavelength shifts and standardization of spectra (such as the SHICRIVM algorithm ${ }^{7}$ ) are used. The unit includes for this purpose a HeCd laser that provides a very strong line at $325 \mathrm{~nm}$. By scanning this line at high-resolution steps the spectral response of the spectroradiometer is obtained.

\section{EVALUATION OF THE UNIT}

One of the main tasks of the QASUME project is to assure the quality and reliability of the spectral measurements made by the spectroradiometer of the unit, and to assess its stability in time and between transportations. After thorough testing in the laboratory, the spectroradiometer was tested against six qualified spectroradiometers both at a small intercomparison campaign and at their home sites. The selection of the instruments was made according to their performance in
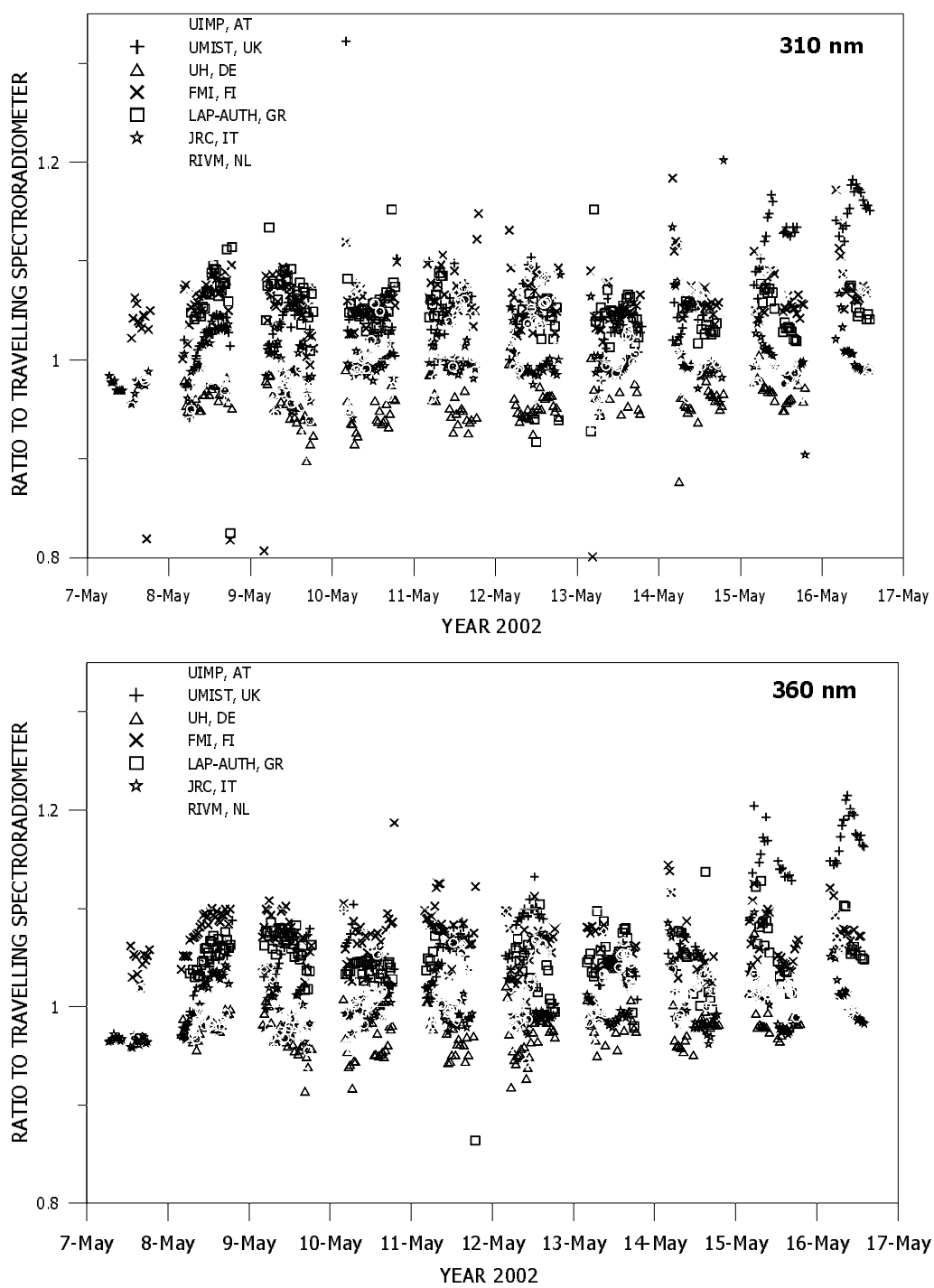

Figure 1. Ratios of global irradiance measured by the core spectroradiometers against the measurement of the travelling insrument at two $5 \mathrm{~nm}$-wide bands centered at $310 \mathrm{mnm}$ (up) and at $360 \mathrm{~nm}$ (down) for the period of the campaign. 
the last few European intercomparison campaigns, and in particular according to the consistency of their results between subsequent campaigns ${ }^{1}$.

\subsection{The campaign}

The intercomparison campaign took place at the JRC in Ispra, Italy from 6 to 17 May 2002. The six instruments with the addition of the local Brewer spectroradiometer of JRC (see Table 1) were installed on the roof of the one-story Solar House building. The horizon was blocked from the east by a building (around $20 \mathrm{~m}$ tall) so the sun could not be seen below about $20^{\circ} \mathrm{SZA}$, while at other directions only short obstacles were obscuring the horizon of the instruments.

Table 1. List of Instruments that participated at the intercomparison campaign

\begin{tabular}{|l|l|}
\hline Instrument types & Institutes \\
\hline Bentham DM 150 & QASUME Traveling spectroradiometer \\
\hline Bentham DTM 300 & University of Innsbruck (UIIMP) \\
\hline Bentham DTM 300 & University of Manchester Institute of Science and Technology (UMIST) \\
\hline Bentham DTM 300 & University of Hanover (UHAN) \\
\hline Brewer MkIII & Aristotle University of Thessaloniki (AUTH) \\
\hline Brewer MkIII & Finnish Meteorological Institute (FMI) \\
\hline Brewer MkIII & Institute for Health \& Consumer Protection (JRC) \\
\hline Dilor XY50 & National Institute of Public Health and the Environment (RIVM) \\
\hline
\end{tabular}

The weather was rather unfavorable for an intercomparison with changing cloud cover and many days of rain. Clear skies were seen only occasionally for periods up to four hours. However, these conditions are most likely to occur dur-

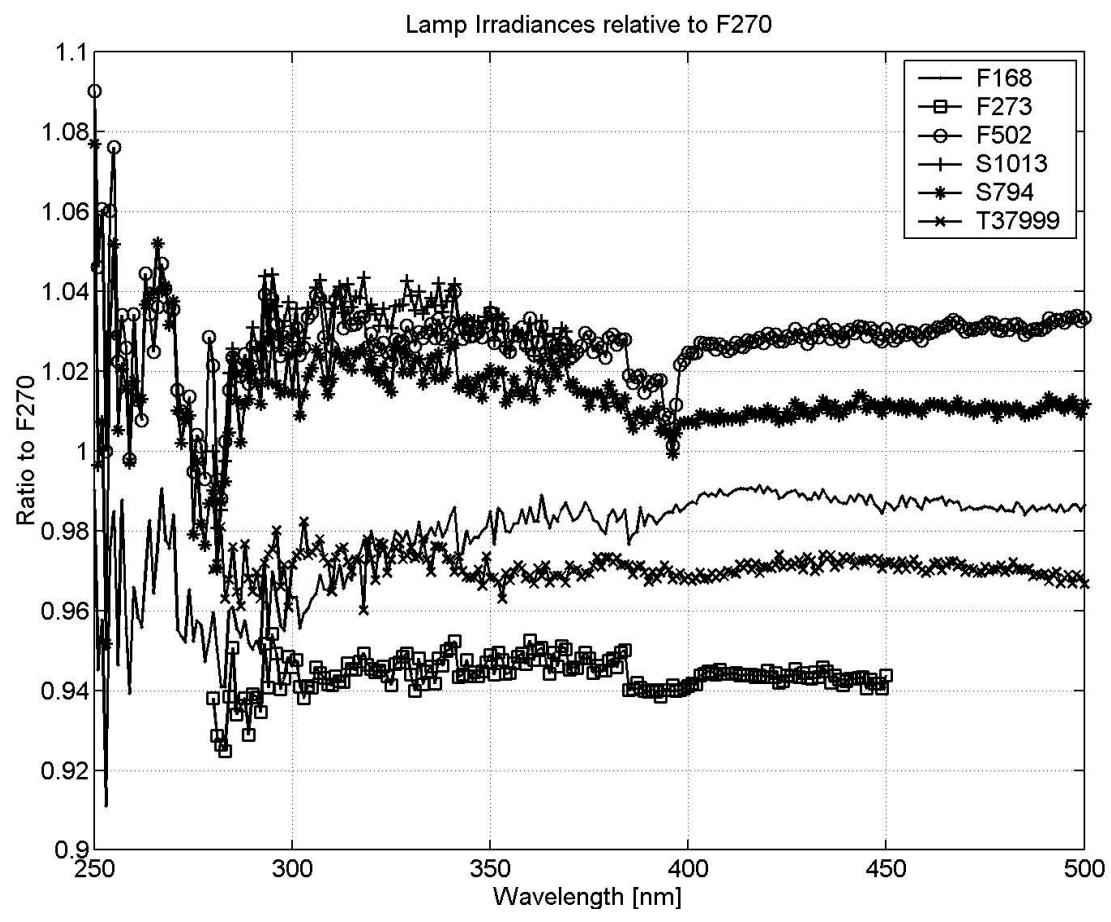

Figure 2. Ratio of irradiance measurements from different calibration standards over the irradiance of lamp F270. The measurements were done in the laboratory by a Bentham DT150 spectroradiometer of JRC. 
ing most of the visits of the traveling unit, offering a good chance to test the performance of the instruments but also the comparison methods under adverse conditions.

All spectra collected during the campaign were corrected for wavelength shifts and standardized to $1 \mathrm{~nm}$ triangular slit function in order to eliminate the significant wavelength structure in the ratios imposed by the different slit functions of the instruments ${ }^{1}$. This was done with the aid of the SHICRIVM ${ }^{7}$ algorithm. Spectral ratios of all instruments against the traveling spectroradiometer were constructed and averages over $5 \mathrm{~nm}$ around selected wavelengths are shown if Fig. 1. It appears from this figure that the overall agreement among the instruments lies within $15 \%$ to $20 \%$. Individually one can detect small diurnal variations in the ratio of most instruments, but also discrepancies in the ratio of UMIST and to a lesser extend of UIIMP. The first could be attributed to differences in the angular response of the instruments in association with the variable sky conditions due to clouds or rain. The later were caused mainly by humidity in the input optics of the two instruments, which affected their sensitivity, and possibly to azimuthal effects in the input optics.

The remaining discrepancies among the various instruments (essentially differences in the absolute scale) are caused mainly by the use of different calibration sources. This problem appears any time that independent instruments are compared $^{1}$, and it is an open issue in UV spectroradiometry. Differences of up to $9 \%$ were found in a recent study where standards from different laboratories were compared ${ }^{8}$. To determine the expected discrepancy due to lamps in this campaign, all calibration lamps of the participating institutes were compared in the laboratory using the spare double monochromator spectroradiometer of JRC, a Bentham DT 150. The spectrometer was equipped with a fiber so it could measure both FEL and DXW type lamps, i.e. in horizontal and vertical beam configuration respectively. Control scans on the same lamp of JRC were performed each time the fiber was moved from the vertical to horizontal configuration. These scans assured that instrument's sensitivity remained stable to within about $1 \%$ during the whole exercise, thus any discrepancies between the lamp measurements are attributable to the calibration of each lamp (Fig. 2).

From this figure it appears that the calibration standards of the different institutes differ and their differences range within about $10 \%$ at the entire wavelength range. Taking into account the expected differences between the measurements of the various instruments due to the differences in their calibration sources, the agreement shown in Figure 1 becomes generally better.

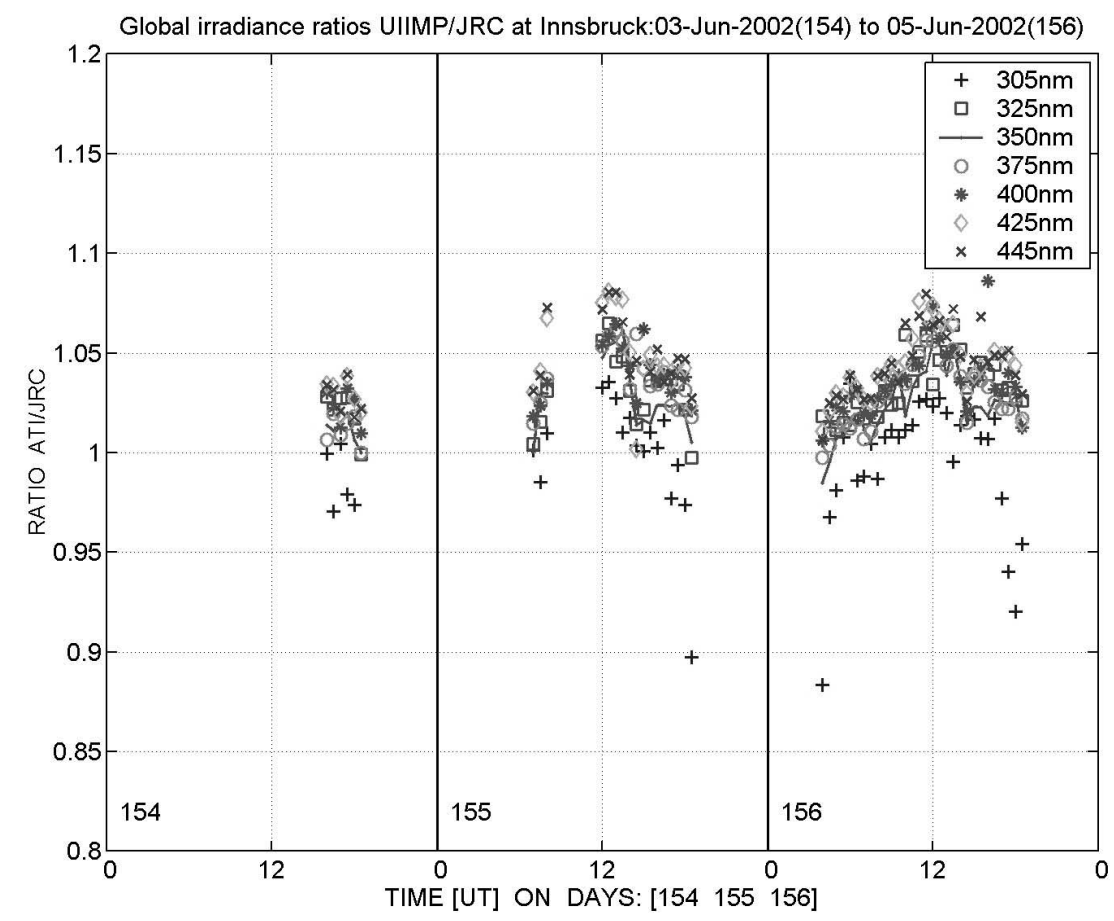

Figure 3. Ratio of global irradiance measurements at selected wavelengths between the UIIMP and the travelling instrument, during three days of comparisons. 


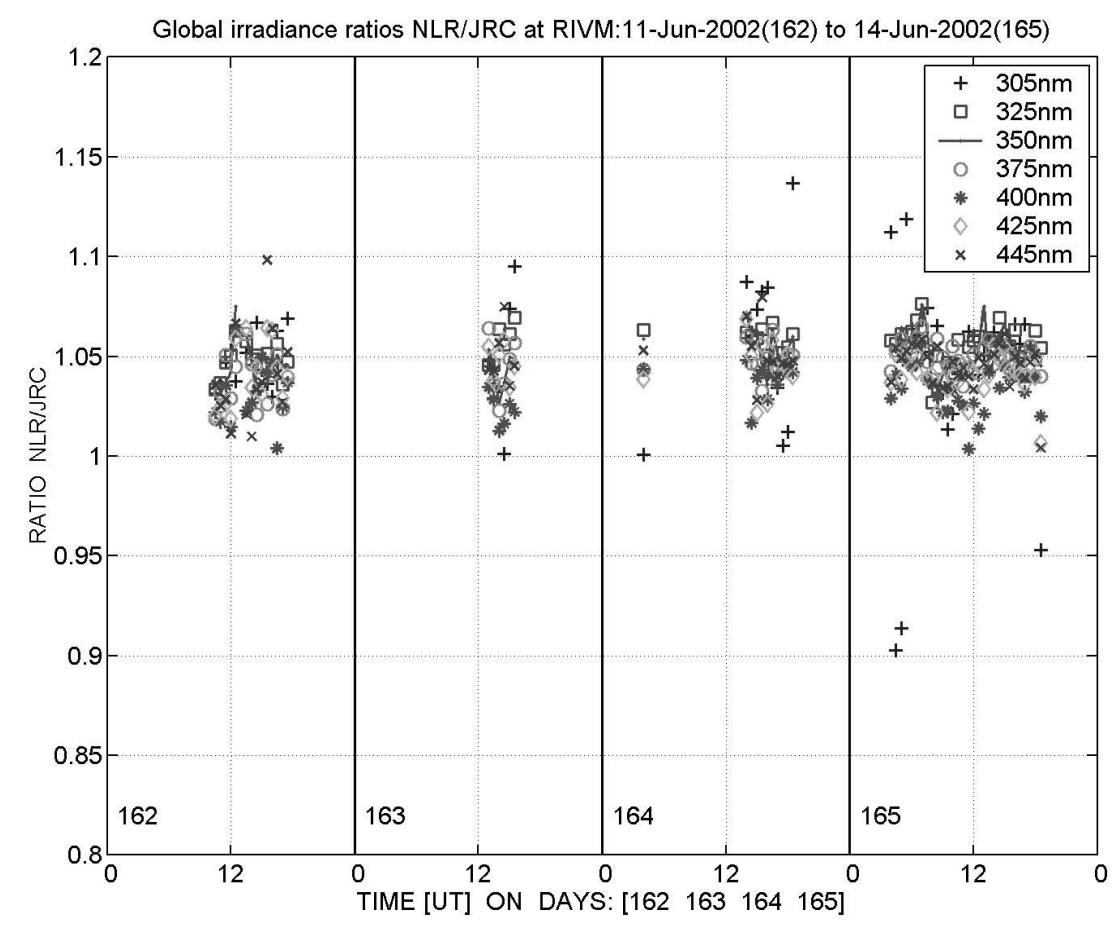

Figure 4. Ratio of global irradiance measurements at selected wavelengths between the RIVM and the travelling instrument, during four days of comparisons.

\subsection{Evaluation round}

The objective of the evaluation round is to confirm that the traveling spectroradiometer compares the same with the core instruments when the comparison is made at their home sites. The core spectroradiometers are assumed to be stable after the transportation to their home site since they are calibrated with the same standard sources, as in the campaign. Therefore repeatable results between each of the core instruments with the campaign results would prove the stability of the traveling instrument. So far five visits have been completed, but only from two of them the results are already processed and presented here; the first at the University of Innsbruck (Fig. 3) and the second at the National Institute of Public Health and the Environment (Fig. 4).

The comparisons at UIIMP started in the afternoon of 3 June and ended in the evening 5 June. The weather was cloudy with sunshine intervals in the first two days and overcast on the third day. The global irradiance measured by the UIIMP spectroradiometer was 3-5\% higher relative to the measurements of the traveling instrument for wavelengths longer of $310 \mathrm{~nm}$. Between 300 and $310 \mathrm{~nm}$ the radiation measured by UIIMP progressively diminishes by about $5 \%$ relative to the traveling instrument. This relative change with wavelength is as yet unexplained. Partly, it could be caused by the difference in the calibration lamps below $330 \mathrm{~nm}$. One possible explanation could be the difference in resolution between the two spectroradiometers, which the analysis software is not able to fully compensate for. The variability between the two spectrometers has amplitude of 5\%, which might be systematic and could be due to variations in temperature of either system.

The comparisons at RIVM started at noon of June 11, and ended in the evening 14 June. The weather was variable, mostly cloudy with very short intervals of sunshine and longer intervals of rain. The mean global irradiance measured by the RIVM spectroradiometer was about 4-6\% higher compared to the traveling instrument at all wavelengths, which is consistent with the behavior of the two instruments during the intercomparison campaign. The variability of the measurements during the whole measuring period was of the order of 2-3\%about the mean without any systematic diurnal feature.

After the completion of its evaluation, a pilot application will follow, by transporting the unit to selected - and reachable by road - European Institutes conducting spectral UV measurements, where the spectroradiometer will operate in paral- 
lel with the local instrumentation for a few days acting as a comparison reference. In addition, the local instruments will be characterised for their spectral resolution and angular response, information that are considered necessary for the complete assessment of their performance.

\section{CONCLUSIONS}

The establishment of a transportable unit to act as reference for providing quality assurance to spectral measurements made at various sites over Europe is the main objective of the QASUME project. The spectroradiometer of the unit is evaluated from the results of an intercomparison campaign which proved that its performance is stable and satisfactory at least with most of the core instruments that acted as comparison references. Part of the differences between instruments is attributed to the different calibration standards. A few instruments behaved abnormally during the campaign, with most probable reason being the humidity dependence of the input optics under the adverse conditions of the campaign.

A second phase of its evaluation has started in June 2002, aiming at testing the stability of the transportable spectrometer after its transportation from place to place. The first two comparisons at different sites showed that the unit behaves satisfactorily in most of the time, with some small unexplained deviations, which are expected to be traced after the completion of the evaluation round and the analysis of the results.

\section{ACKNOWLEDGEMENTS}

The work is supported by the European Commission through the project QASUME (Contract $\mathrm{N}^{\circ}$ EVR1-CT200140011).

\section{REFERENCES}

1. Scientific Assessment of ozone depletion: 1998, Global Ozone Research and Monitoring project Rep. No. 44, World Meteorological organisation, Geneva, 1998).

2. G. Seckmeyer, A. Bais, G. Bernhard, M. Blumthaler, C.R. Booth, P. Disterhof, P. Eriksen, R.L. McKenzie, M. Miyauchi, and C. Roy, Instruments to measure solar ultraviolet radiation Part 1: Spectral instruments, WMO/GAW Report No. 125, World Meteorological Organization, Geneva, 2000.

3. A. R. Webb, B. G. Gardiner, T. J. Martin, K. Leszcynski, J. Metzdorf, V. A. Mohnen, , Guidelines for Site Quality Control of UV Monitoring, WMO/GAW Report No. 126, World Meteorological Organization, Geneva, 2000.

4. A. F. Bais, S. Kazadzis, D. Balis, C. S. Zerefos, and M. Blumthaler, Correcting global solar UV spectra recorded by a Brewer spectroradiometer for its angular response error, Appl. Opt. 37, 27, 6339 - 6344, 1998.

5. G. Bernhard and G. Seckmeyer, The uncertainty of measurements of spectral solar UV irradiance, J. Geophys. Res 104, 14,321-14,345, 1999.

6. A. F. Bais, B. G. Gardiner, H. Slaper, M. Blumthaler, G. Bernhard, R. McKenzie, A. R. Webb, G. Seckmeyer, B. Kjeldstad, T. Koskela, P. Kirsch, J. Gröbner, J. B. Kerr, S. Kazadzis, K. Leszczynski, D. Wardle, C. Brogniez, W. Josefsson, D. Gillotay, H. Reinen, P. Weihs, T. Svenoe, P. Eriksen, F. Kuik, A. Redondas, SUSPEN intercomparison of ultraviolet spectroradiometers, J. Geophys. Res. 12, pp. 509-12,526, 2001.

7. H. Slaper, H. A. J. M. Reinen, M. Blumthaler, M. Huber, and F. Kuik, Comparing ground-level spectrally resolved solar UV measurements using various instruments: a technique resolving effects of wavelength shift and slit width, Geophys. Res. Lett. 22, pp. 2721-2724, 1995.

8. J. Gröbner, D. Rembges, A. Bais, M. Blumthaler, T. Cabot, W. Josefsson, T. Koskela, T. M. Thorseth, A. R. Webb, U. Wester, Quality assurance of reference standards from nine European solar-ultraviolet monitoring laboratories, Appl. Opt. 41, pp. 4278-4282, 2002 